\title{
Ossifying Fibroma of Dorsal Spine in a Postpartum Female: A Rare Case Report
}

\author{
Musali Siddartha Reddy ${ }^{1}$ Gollapudi Prakash Rao ${ }^{1} \quad$ Mohammed Imran ${ }^{1} \quad$ Uday Goutam Nookathota \\ ${ }^{1}$ Department of Neurosurgery, Gandhi Medical College and \\ Hospital, Secunderabad, Telangana, India

\begin{abstract}
Address for correspondence Musali Siddartha Reddy, MBBS, MS, Mch, Department of Neurosurgery, Gandhi Medical College and Hospital, 4th Floor, Padmarao Nagar, Secunderabad 500003, Telangana, India (e-mail: siddarthareddy123@gmail.com).
\end{abstract}

\begin{abstract}
Keywords

- ossifying fibroma

- monostotic

- postpartum

- thoracic spine

A rare case of monostotic ossifying fibroma of the dorsal spine in a postpartum woman is being described. Ossifying fibromas of the spine are very rare tumors. They are components of benign fibro-osseous lesions. We report a case of an 18-year-old woman, who presented with complaints of weakness of both the lower limbs in the immediate postpartum period and was diagnosed with ossifying fibroma of the dorsal [D3] vertebral body. The tumor was excised followed by spinal stabilization. Histopathologic findings were consistent with ossifying fibroma. Postoperative period was uneventful. Monostotic variant of ossifying fibroma in the dorsal spine is an extremely rare tumor, and its presence in the postpartum period adds on to the diagnostic dilemma. Hence this case report can be kept in mind while evaluating a case presenting with complaints of weakness of both the lower limbs in the immediate postpartum period.
\end{abstract}

\section{Introduction}

Ossifying fibromas are very rare tumors. They commonly occur in women with a peak incidence in the third and fourth decades. They more commonly occur in the mandible and maxilla. They are uncommon in the spine, and the monostotic variant of the dorsal spine is very rare. We report a case of an 18-year-old woman with D3 vertebral ossifying fibroma. Clinical significance and management of this lesion are discussed with the review of the literature.

\section{Case Report}

An 18-year-old postpartum woman presented with complaints of difficulty in walking for 10 days. She gave birth to her first child 14 days earlier by normal vaginal delivery. The antenatal course was uneventful. There was no history of trauma, drug abuse, or physical exertion. The patient was able to walk for 4 days after delivery following which she developed difficulty in walking, which was gradual in onset and progressive in nature. Initially she walked with support but later could not do so even with support. There was history of dull mid thoracic pain of moderate intensity for 10 days. There was history of bladder retention and overflow incontinence for 8 days. There was no history of tingling and paresthesias in both the lower limbs. There was no history of fever. On examination, power was $0 / 5$ (Medical Research Council [MRC] grading) in both the lower limbs. All sensations were preserved. In T2W/STIR magnetic resonance imaging (MRI) hyperintensity was noted involving the D3 vertebral body with posterior cortical bulge with a decrease in vertebral body height. MRI contrast revealed intense enhancement with paravertebral epidural components causing spinal canal narrowing and cord compression ( - Fig. 1A, B). There was D3 vertebral body destruction with adjacent soft tissue thickening ( - Fig. 2). Computed tomography (CT)-guided biopsy was advised, which revealed a spindle cell tumor. D3 and D4 laminectomy and excision biopsy of the lesion was done followed by spinal stabilization. The specimen was sent for histopathologic examination (biopsy) and immunohistochemistry. $\mathrm{K}_{\mathrm{i}}-67$ was sparsely positive $(<1 \%)$, indicating that the lesion was benign in nature ( - Fig. $\mathbf{3}$ ), and a diagnosis of ossifying fibroma was established. Postoperative period was uneventful, and there was no improvement in the muscle strength (MRC 0/5). The patient was later lost to follow-up. received

November 6, 2018 accepted

December 13, 2018

published online

August 22, 2019
DOI https://doi.org/

10.1055/s-0039-1695087

ISSN 2277-954X
C2019 Neurological Surgeons'

Society of India
License terms

(1) (1) $\Theta$ 

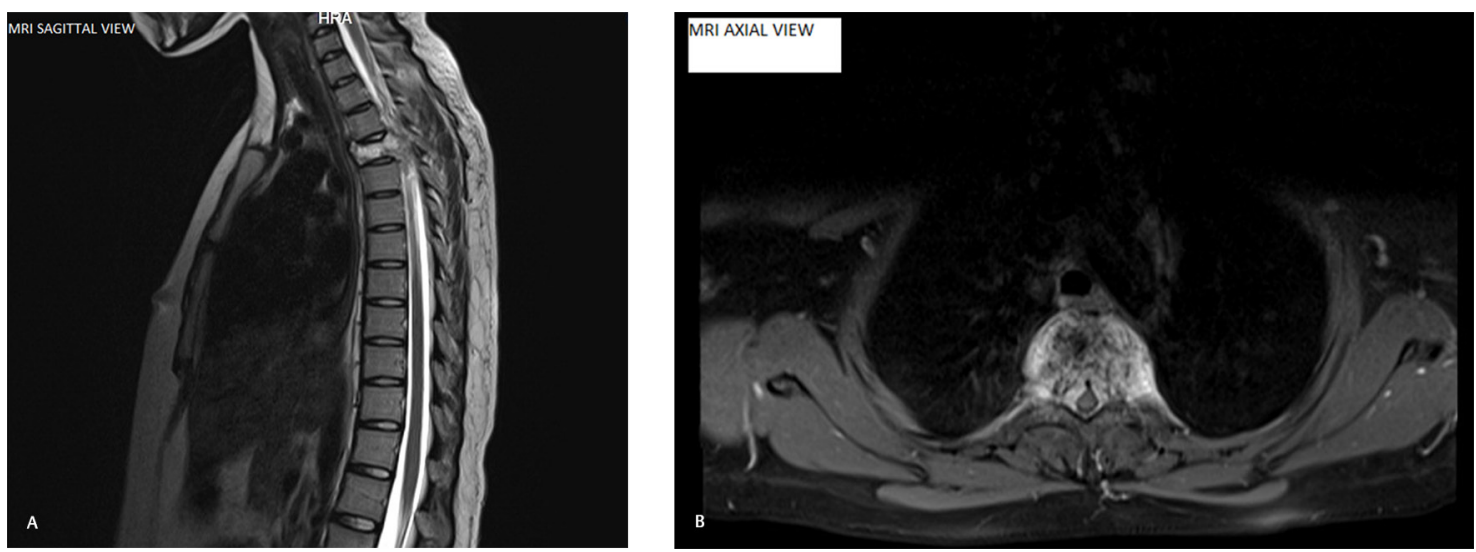

Fig. 1 (A, B) T2W/STIR hyperintensity noted involving D3 vertebral body with posterior cortical bulge with decrease in vertebral body height. Intense enhancement was noted with paravertebral epidural components causing spinal canal narrowing and cord compression. MRI, magnetic resonance imaging.

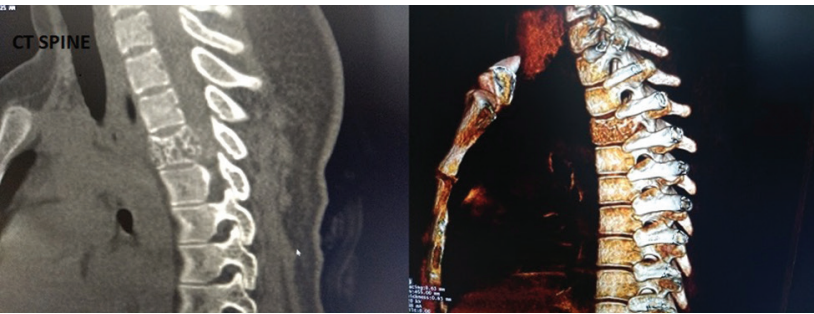

Fig. 2 D3 vertebral body destruction with adjacent soft tissue thickening. CT, computed tomography.

\section{Discussion}

Ossifying fibroma was recognized by Lichtenstein in $1938 .{ }^{1}$ It was first reported in the spine by Ohyama et al in $1992 .{ }^{2}$ It is a component of the benign fibro-osseous lesion (BFOL). It is characterized by replacement of normal bone by cellular fibrous tissue and newly formed osseous or so-called cemento-osseous deposits. Skeletal involvement can be mono-ostotic/polyostotic (associated with endocrine abnormalities). Ossifying fibroma accounts for $7 \%$ of benign bone lesions, and prevalence of spinal involvement is very low particularly in monostotic forms. ${ }^{3}$ It is more common in women. It occurs in patients before the age of 40 years with a peak incidence in the third to the fourth decade. ${ }^{4}$ It is more common in the mandibles and maxilla. ${ }^{4}$ It also manifests in the calvarium (frontal and temporal) and long bones. The vertebral body is more commonly involved due to a relative large amount of the cancellous bone. Thoracic monostotic vertebrae involvement is extremely rare, which has been reported in this case. It is caused by postzygotic mutation in guanine nucleotide stimulatory protein (GNAS1) gene, grows slowly, and is asymptomatic initially; symptoms and signs depend on the tumor location. Ossifying fibroma is usually static after growth ceases but is reactivated with pregnancy. ${ }^{5}$ There might be a rapid growth of the lesion because of the presence of hormone-specific receptors in bone cells. Though gonadal steroids profoundly affect bony metabolism, exacerbation of ossifying fibroma in pregnancy is a rare phenomenon. ${ }^{6,7}$ Studies revealed a high-concentration estrogen receptor on osteogenic cells obtained from abnormal areas of the skeleton of patients with monostotic variants.

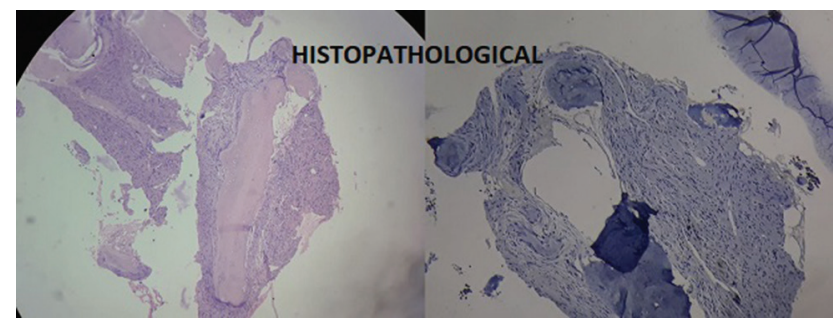

Fig. 3 IHC: Sparsely $\mathrm{K}_{\mathrm{i}}-67$ positive $(<1 \%)$ indicating that the lesion was benign in nature.

Radiographically radiolucent lesions initially but gradually become radiopaque with calcification. There is an expansion of the involved bone with presentation of thin rim of the cortex. CT of ossifying fibroma shows multiple intracortical osteolysis as lucencies with a characteristic sclerotic band. In MRI T1W images are of low signal. T2W images are iso- to high-intensity signals and show enhancement with contrast. ${ }^{8}$ Histologically lesions appear well circumscribed sharply delineated by host lamellar bone. The classic characteristic pattern is that of curvilinear Chinese alphabet spicules of woven bone separated abundant fibrous stroma. ${ }^{9,10} \mathrm{~K}_{\mathrm{i}}-67$ index is sparse in ossifying fibroma.

\section{Treatment}

Treatment depends on the presence of symptoms. Asymptomatic patients are observed every 6 months with serial radiographs. Surgery is indicated when there are persistent pain, neurologic impairment, vertebral collapse, and instability/cord compression. ${ }^{11}$ In a case of spinal involvement, consensus of management has not yet been achieved.

\section{Conclusion}

The thoracic monostotic spinal variant of ossifying fibroma is an extremely rare tumor, which can present in the postpartum period because of the effect of hormones on the tumor growth; hence, it should be kept in mind for evaluation of sudden onset of weakness in the postpartum period. 


\section{Conflicts of Interest}

The authors have no potential conflict of interest.

\section{Funding}

None.

\section{Consent}

The patient and her attendants have given consent for publication of article.

\section{References}

1 Lichtenstein L. Polyostotic fibrous dysplasia. Arch Surg 1938;36(5):874-879

2 Ohyama T, Ohara S, Momma F, Moto A, Nakata Y. Ossifying fibroma of the thoracolumbar spine: a case report and review of the literature. Surg Neurol 1992;37(3):231-235

3 Gogia N, Marwaha V, Atri S, Gulati M, Gupta R. Fibrous dysplasia localized to spine: a diagnostic dilemma. Skeletal Radiol 2007;36(1, Suppl 1):S19-S23

4 Hamilton HB, Tumors of the skull. In: Neurosurgery. 2nd ed. New York, NY: McGraw-Hill; 1996;1503-1528
5 Stevens-Simon C, Stewart J, Nakashima II, White M. Exacerbation of fibrous dysplasia associated with an adolescent pregnancy. J Adolesc Health 1991;12(5):403-405

6 Kaplan FS, Fallon MD, Boden SD, Schmidt R, Senior M, Haddad JG. Estrogen receptors in bone in a patient with polyostotic fibrous dysplasia (McCune-Albright syndrome). N Engl J Med 1988;319(7):421-425

7 Pensler JM, Langman CB, Radosevich JA, et al. Sex steroid hormone receptors in normal and dysplastic bone disorders in children. J Bone Miner Res 1990;5(5):493-498

8 Shah ZK, Peh WC, Koh WL, Shek TW. Magnetic resonance imaging appearances of fibrous dysplasia. $\mathrm{Br} \mathrm{J}$ Radiol 2005;78(936):1104-1115

9 Dorfman HD. New knowledge of fibro-osseous lesions of bone. Int J Surg Pathol 2010;18(3 Suppl):62S-65S

10 Riminucci M, Liu B, Corsi A, et al. The histopathology of fibrous dysplasia of bone in patients with activating mutations of the Gs alpha gene: site-specific patterns and recurrent histological hallmarks. J Pathol 1999;187(2):249-258

11 Stanton RP, Ippolito E, Springfield D, Lindaman L, Wientroub S, Leet A. The surgical management of fibrous dysplasia of bone. Orphanet J Rare Dis 2012;7(1, Suppl 1):S1 